\title{
Microstructure of HR6W Alloy at Elevated Temperature after Prolonged Ageing in Air Atmosphere
}

\author{
A. Zielińshi ${ }^{a, *}$, G. Golański ${ }^{b}$, M. Kierat $^{c}$, M. SROKA $^{d}$, \\ A. MERDA $^{b}$ AND K. SówKA ${ }^{e}$ \\ ${ }^{a}$ Lukasiewicz Research Network - Institute for Ferrous Metallurgy, \\ K. Miarki 12-14, PL 44100 Gliwice, Poland \\ ${ }^{b}$ Czestochowa University of Technology, Institute of Materials Engineering, \\ Al. Armii Krajowej 19, PL 42200 Częstochowa, Poland \\ ${ }^{c}$ Silesian University of Technology, Institute of Material Science, PL 40019 Katowice, Poland \\ ${ }^{d}$ Silesian University of Technology, Department of Engineering Materials and Biomaterials, \\ PL 44100 Gliwice, Poland \\ ${ }^{e}$ ZRE Katowice, Poland
}

Doi: 10.12693/APhysPolA.138.253

*e-mail: azielinski@imz.pl

\begin{abstract}
The article conducts research aimed to determine the impact of long-term ageing $(20000$ hours $)$ at $700{ }^{\circ} \mathrm{C}$ and $750^{\circ} \mathrm{C}$ on the microstructure of the $\mathrm{HR} 6 \mathrm{~W}$ alloy. Research results indicate that long-term exposure to high temperature causes significant changes in the microstructure of the tested alloy. The effect of increasing the ageing temperature to $750^{\circ} \mathrm{C}$ caused a significant acceleration of the precipitation process after just $1000 \mathrm{~h}$. At that time their coagulation and an increase in the size of the Laves phase precipitates inside the austenite grains were observed, apart from the $\mathrm{M}_{23} \mathrm{C}_{6}$-type precipitation grids along the austenite grain boundaries. The extension of the ageing time to $20000 \mathrm{~h}$ at $750^{\circ} \mathrm{C}$, however, contributed to a significant increase in the size of the Laves phase precipitates inside the austenite grains.
\end{abstract}

topics: HR6W, microstructure, alloys, precipitation, ageing

\section{Introduction}

One of the directions to ensure energy security and environmental protection is to reduce the combustion of fossil fuels while increasing the efficiency of high-power units. The most promising technology to improve the efficiency of conventional power plants is possessed by ultra-supercritical power plants [1-4]. To obtain high steam parameters at $700-760^{\circ} \mathrm{C}$ and $28-35 \mathrm{MPa}$ in these power units, the selection of appropriate creep- and heatresistant construction materials is required.

Ferritic steels containing 9-12\% Cr which are characterised by high creep strength are widely used for components of the main steam pipelines operating at steam temperatures up to $620^{\circ} \mathrm{C}$. On the other hand, austenitic steels containing 18-25\% Cr show significant restrictions on use for thick-walled components, which results from resistance to thermal fatigue that is lower due to the higher thermal expansion coefficient of these steels [5-8]. One of the modern materials which stands as a candidate for thick cross-section components is $\mathrm{HR} 6 \mathrm{~W}$ (23Cr- $45 \mathrm{Ni}-6 \mathrm{IN}-\mathrm{Nb}-\mathrm{Ti}-\mathrm{B})$ alloy.

This alloy was developed in Japan as a material for components operating at $700 \div 800^{\circ} \mathrm{C}$. At present, HR6W alloy is mainly recommended for thick-walled structural components, such as primary steam pipelines or headers. Mechanical properties of HR6W alloy, i.e., creep resistance and stability of the microstructure at above $650^{\circ} \mathrm{C}$, are comparable to properties of the nickel-base superalloy, referred to as Alloy 617 [9]. The chemical composition of HR6W alloy was selected so that its strengthening can be provided by tungsten atoms (solid-solution strengthening) and Laves-phase precipitates (precipitation strengthening). Due to high Cr content of $\approx 23 \%$, this alloy is characterised by better steam oxidation and hot corrosion resistance than ferritic steels $[9,10]$. Therefore due to its performance, HR6W alloy is an intermediate construction material between austenitic steels and nickel superalloys. This article presents the results of microstructural investigations of HR6W alloy after ageing at 700 and $750^{\circ} \mathrm{C}$.

\section{Experiment and Materials}

The material used in the investigations was HR6W (23Cr-45Ni-6W-Nb-Ti-B) alloy in the asreceived condition delivered as a coil specimen of $\Phi 38 \times 8.8 \mathrm{~mm}$. The microstructural investigations were carried out on microsections taken perpendicularly to the axis of the tube. The investigations were performed on material in the as-received condition and after long-term ageing at 700 and $750{ }^{\circ} \mathrm{C}$ for $20000 \mathrm{~h}$. 
Chemical composition of the test material with reference to the requirements of VdTUV559/2 09.2011.

\begin{tabular}{l|c|c|c|c|c|c|c|c|c}
\hline \hline \multirow{2}{*}{ Source } & \multicolumn{10}{c}{ Content [\%wt] } \\
\cline { 2 - 9 } & $\mathrm{C}$ & $\mathrm{Si}$ & $\mathrm{Mn}$ & $\mathrm{Cr}$ & $\mathrm{W}$ & $\mathrm{Ni}$ & $\mathrm{Fe}$ & $\mathrm{Ti}$ & $\mathrm{Nb}$ \\
\hline standard & 0.10 & 1.0 & 1.50 & $21.5 \div 24.5$ & $6 \div 8$ & $\mathrm{bal}$ & $20 \div 30$ & 0.20 & 0.35 \\
check analysis & 0.09 & 0.95 & 1.32 & 24.15 & 7.95 & 45.0 & 23.2 & 0.18 & 0.29
\end{tabular}

The microsections were ground and polished, and then electrolytically etched with $50 \% \mathrm{HNO}_{3}$ solution. The images of the microstructure of the test alloy were observed and recorded with SEM (Inspect F), and the identification of precipitates was confirmed with TEM (TITAN 80-300). The chemical composition of the test material with reference to the requirements of the relevant standard is presented in Table I.

\section{Results and discussion}

The heat-resistant / creep-resistant austenitic alloys are delivered in the as-solution heat-treated condition to provide the microstructure without precipitates [9]. HR6W alloy is heat treated at $1190-1253^{\circ} \mathrm{C}$ and then cooled in water. The chemical composition of the analysed alloy includes very strong carbide formers, i.e., niobium and titanium. In the matrix, the primary precipitates can be observed inside the grains and nearby the grain boundaries (Fig. 1). The identifications revealed the presence of both titanium-rich and niobium-rich precipitates (Fig. 2). In addition to binding carbon and/or nitrogen atoms, the primary precipitates are to inhibit the grain growth during the thermomechanical treatment [11]. In addition, single $\mathrm{M}_{23} \mathrm{C}_{6}$ carbides were also observed at the grain boundaries in the as-received condition (Fig. 3). The primary precipitates of $\mathrm{M}_{23} \mathrm{C}_{6}$ in $\mathrm{HR} 6 \mathrm{~W}$ alloy in the as-received condition were also identified in [9]. In the microstructure, numerous annealing twins were also visible.

Long-term ageing of the test alloy at 700 and $750{ }^{\circ} \mathrm{C}$ for $20000 \mathrm{~h}$ contributed to the occurrence of intensive precipitation processes. Numerous



Fig. 1. Microstructure of HR6W alloy in the asreceived condition.
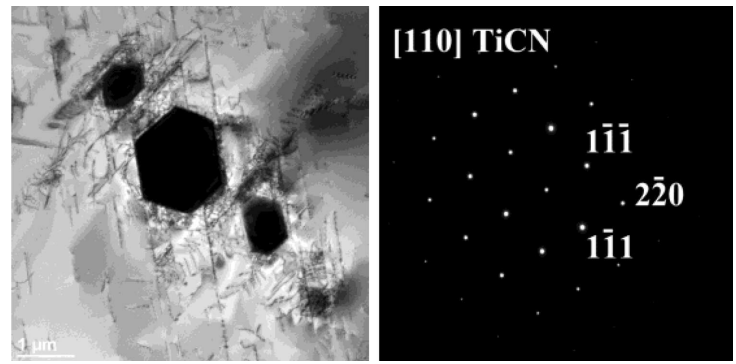

Fig. 2. Primary TiN precipitate in HR6W alloy in the as-received condition, TEM.
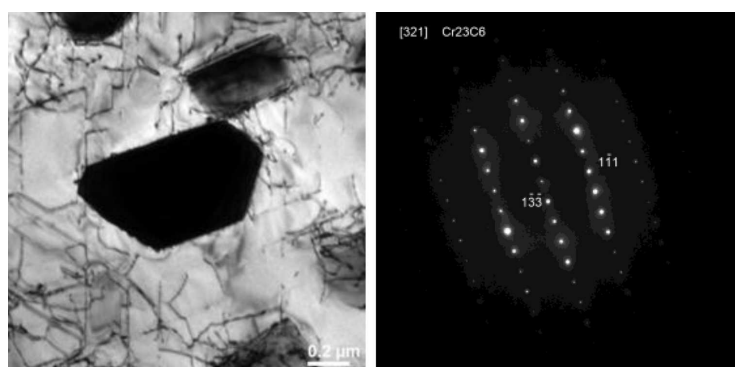

Fig. 3. Primary $\mathrm{M}_{23} \mathrm{C}_{6}$ precipitate in HR6W alloy in the as-received condition, TEM.

precipitation processes were observed inside the grains and at the grain boundaries, as well as at the twin boundaries. The amount of precipitates with varying morphologies at the grain and twin boundaries was so high that they formed the socalled continuous grid of precipitates in places. In the test alloy, the occurrence of globular $\mathrm{M}_{23} \mathrm{C}_{6}$ carbides and elongated Laves-phase precipitates were noticed at the grain and twin boundaries (Figs. 4, 5). The grain boundaries are the preferred sites for the precipitation of secondary phases due to their increased energy and provide the ways for easy diffusion compared to the interior of the grain. In the test alloy after ageing at both 700 and $750{ }^{\circ} \mathrm{C}$, no $\sigma$-phase precipitates were observed at the grain boundaries. This confirms the positive impact of adding tungsten on shifting towards longer nucleation times for this disadvantageous phase [9].

The $\mathrm{M}_{23} \mathrm{C}_{6}$ carbides in austenitic alloys (with no copper added) are the first secondary precipitates in the microstructure of these materials. The precipitation of $\mathrm{M}_{23} \mathrm{C}_{6}$ carbides in these alloys is related to the reduction in carbon solubility with increase in temperature. During the initial stage of 


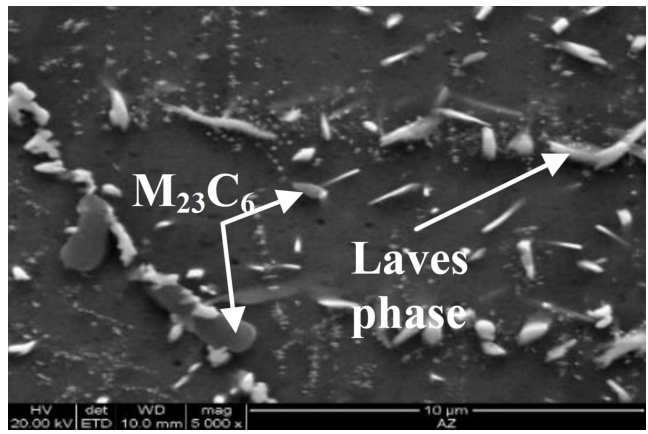

Fig. 4. Microstructure of HR6W alloy after ageing at $700{ }^{\circ} \mathrm{C} / 20000 \mathrm{~h}$.

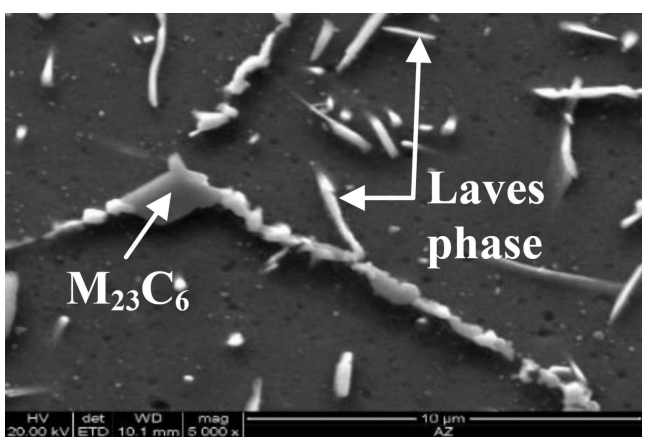

Fig. 5. Microstructure of HR6W alloy after ageing at $750^{\circ} \mathrm{C} / 20000 \mathrm{~h}$.

service, fine $\mathrm{M}_{23} \mathrm{C}_{6}$ precipitates at the grain boundaries improve creep strength by preventing slip at the grain boundaries. The $\mathrm{M}_{23} \mathrm{C}_{6}$ precipitates also inhibit the grain migration, thus delaying the matrix softening processes [12].

Low stability of $\mathrm{M}_{23} \mathrm{C}_{6}$ carbides leads to their rapid growth and the formation of the so-called continuous grid of precipitates, which results in the loss of their favourable effects. Based on the experience with using of 9-12\% Chromium steels showed that the introduction of boron to the material causes the precipitation of $\mathrm{M}_{23}(\mathrm{C}, \mathrm{B})_{6}$ carboborides. These are characterised by higher stability and keeping the dispersive form for an extended time compared to $\mathrm{M}_{23} \mathrm{C}_{6}$ carbides. In turn, the Laves-phase precipitates in the test alloy were considered to be favourable in the case of dispersive form of these precipitates. Similarly to $\mathrm{M}_{23} \mathrm{C}_{6}$ carbides, the increase in the size of Laves-phase precipitates results in reduction of the creep and crack resistance. The micro-addition of boron has also a positive effect on the stability and dispersion of the Laves phase. Numerous large precipitates at the grain boundaries reduced the coherence of grain boundaries and create favourable conditions for low-energy intercrystalline cracking. Inside grains, numerous precipitates of varying morphologies occurred. A relatively lower number of particles observed in the alloy aged at $750{ }^{\circ} \mathrm{C}$ indicates the acceleration of their growth processes (Figs. 3, 5).

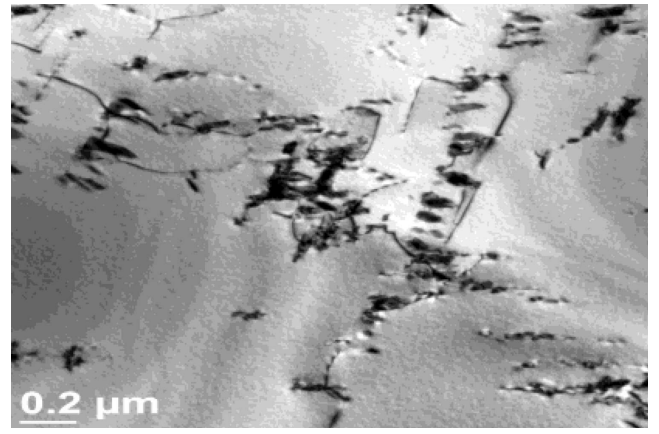

Fig. 6. Dislocation structure of HR6W alloy after long-term ageing $\left(20000 \mathrm{~h} / 750^{\circ} \mathrm{C}\right)$.

Assuming the constant volume fraction in accordance with the Ostwald's law, the increase in the size of particles at $750{ }^{\circ} \mathrm{C}$ contributes to the reduction in their number. This may result in the reduction of the amount of barriers to free dislocation movement (distance between particles increases). In relation to the primary MX precipitates, the identification of the precipitates inside the grains revealed the presence of the Laves phase and $\mathrm{M}_{23} \mathrm{C}_{6}$ particles. The ratio of $\mathrm{M}_{23} \mathrm{C}_{6}$ carbides precipitated inside the grains to those precipitated at the grain boundaries is $7 \div 93$. The precipitates inside the grains have a dispersive form which, assuming the effect of the Orowan mechanism, makes them more effective barriers to dislocation movement. Some of the particles inside the grains are also precipitated on dislocations (Fig. 6), resulting in the pinned dislocations and the formation of characteristic parallel lines.

The presence of numerous precipitates in the microstructure of the test alloy after ageing causes the precipitation strengthening. In fact, the precipitation strengthening of specific alloy depends on the amount and size (dispersion), as well as the arrangement of secondary precipitates in the matrix, and this is the predominant mechanism for this group of materials. The secondary-phase precipitation processes in austenitic alloys lead to the increase in strength properties and hardness while reducing the plastic properties and toughness [13].

\section{Conclusions}

The investigations were carried out on HR6W nickel-base alloy designed for the components of (thick-walled) installations in ultra-supercritical boilers. The analysed alloy was aged at two temperatures of 700 and $750^{\circ} \mathrm{C}$ with holding time up to $20000 \mathrm{~h}$. The ageing of the test alloy resulted mainly in intense precipitation processes inside the grains and at the grain and twin boundaries. In addition to the primary MX precipitates, the $\mathrm{M}_{23} \mathrm{C}_{6}$ carbides and Laves phase were observed in the microstructure. The precipitated particles formed a continuous grid at the grain/twin 
boundaries. Inside the grains, there were numerous precipitates of varying morphologies. At the lower ageing temperature of $700^{\circ} \mathrm{C}$, a relatively more dispersive form of precipitates was observed inside the grains, compared to those at the higher temperature of the experiment.

\section{References}

[1] R. York, S.E. Bell, Energy Res. Soc. Sci. 51, 40 (2019).

[2] M. Sroka, A. Zielinski, J. Mikuła, Arch. Metall. Mater. 61, 969 (2016).

[3] Śliwa, W. Kwaśny, M. Sroka, R. Dziwis, Metalurgija 56, 422 (2017).

[4] P. Snopiński, M. Król, T. Tański, B. Krupińska, J. Therm. Anal. Calorim. 133, 379 (2018).

[5] A. Zieliński, M. Sroka, M. Miczka, A. Sliwa, Arch. Metall. Mater. 61, 753 (2016).
[6] A. Zieliński, J. Dobrzański, H. Purzyńska, G. Golański, Mater. Test. 57, 859 (2015).

[7] T. Tański, P. Snopinski, W. Borek, Mater. Manuf. Process. 32, 1368 (2017).

[8] M. Sroka, A. Zieliński, G. Golański, Acta Phys. Pol. A 135, 207 (2019).

[9] T. Tokairin, K.V. Dahl, H.K. Danielsen, F.B. Grumsen, T. Sato, J. Hald, Mat. Sci. Eng. A-Struct. 565, 285 (2013).

[10] A. Zieliński, J. Dobrzański, H. Purzyńska, R. Sikora, M. Dziuba-Kałuża, Z. Kania, Arch. Metall. Mater. 62, 2057 (2017).

[11] W. Sen, X. Qin, J. Guo, L. Lou, L. Zhou, Mater. Des.69, 81 (2015).

[12] T. Sourmail, Mater. Sci. Technol. Lond. 1, 1 (2001).

[13] G. Golański, A. Zielińska-Lipiec, A. Zieliński, M. Sroka, J. Mater. Eng. Perform. 26, 1101 (2017). 